corresponding improvement in the clinical symptoms or there was a rapid progression out into the lung structure with the development, as a rule, of a bronchopneumonia.

In a few instances, the pneumonia was lobar, being confined to one or more lobes. In some cases the infection was so severe that a general pulmonary edema developed with almost complete obliteration of the normal chest shadows. Associated with this severe pulmonary edema was an effusion into the pericardial sac. In examining these cases roentgenographically an attempt was made to follow the regular routine, which consisted of fluoroscopy first, and then the making of plates. Some patients were so very ill that only a minimum amount of observation could be attempted. On fluoroscopy in the mild cases one was struck with the density of the hilum shadows and the marked infiltration of the larger bronchi with an increase in the mediastinal density. In these cases the movements of the diaphragm were unimpaired. In the definite pneumonias the findings would be as above with a bronchopneumonia involving both lungs, as a rule, although a number of cases of unilateral bronchopneumonia were observed.

In these cases the movements of the diaphragm were unimpaired unless the infection was very extensive. These cases at times were so severe that the entire chest became involved, with here and there small islands of apparently normal lung tissues. It was remarkable to see these patients and wonder how they could possibly breathe. A great number of cases of lesser severity were noted. Those that were definitely lobar pneumonia showed involvement of one or more lobes, usually beginning in the lower right. They appeared to be less toxic and were easier to handle. The respiratory movements were always rapid, and the movements of the diaphragm on one or both sides were impaired, and frequently fluid was found in the pleural cavity.

This type of pneumonia was the exception. In these conditions the heart was of interest. In the severe cases of pulmonary edema the heart shadow was obscured, owing to the edema and the fiuid in the pericardial sac. A number of hearts in the bronchopneumonia types appeared distinctly bottle shaped. On repeated observations this was found to be due, not to fluid in the pericardial sac, but to a degeneration of the heart muscle with dilatation. In the lobar pneumonias the heart was found, as a rule, enlarged, and was a striking feature along with the impairment of the movements of the diaphragm.

Multiple abscess formation in the lobular type and empyema in the lobar type were also observed, although the latter was not nearly so frequent as in the pneumonias of last fall. Another feature worthy of note was the apparent similarity of these bronchopneumonias to the findings in an acute pulmonary tuberculosis. It would be impossible from roentgen examination alone to differentiate these cases, even after apparent recovery from the pneumonia.

It is with a great deal of hesitancy that we should diagnose cases of tuberculosis in individuals who have had influenza or influenzal pneumonia, even months after apparent recovery. In a limited number of cases bronchiectasis was noted, nearly always unilateral and mostly confined to the lower right chest.

Harry Fi. Friedman, M.D., Chelsea, Mass.

Lieutenant, Junior Grade, U. S. N. R. F.; Roentgenologist, U. S. Naval Hospital.

\section{"STUDIES OF ROENTGENOGRAMS OF THE ACCESSORY NASAL SINUSES"}

To the Editor:-In The Journal, Nov. 9, 1918, p. 1555, Dr. Max Unger of New York, in a preliminary note, describes an alleged new method for the study of the nasal accessory sinuses with the roentgen rays.

As a matter of fact, this method was described very accurately by Dr. George E. Pfahler of Philadelphia, in an article published in the Laryngoscope, July, 1916. Every detail mentioned by Dr. Unger appears in Dr. Pfahler's original paper, with considerable enlargement. The only variation in the method consists in the exact size of the film that is used. Dr. Pfahler even described the possibility of cocainization of the pharynx in some hypersensitive patients. He also mentioned the advantages of the method in studying the relations of the floor of the antrum to the neighboring teeth.

Since the publication of this method by Dr. Pfahler, it has been used very generally by roentgenologists throughout the country. I myself have employed it several times.

The method is mentioned on page 208 of Knox's "Radiography," second edition.

Dr. Unger states that his report is a preliminary one and deals only with the use of this method on the cadaver. Yet this is a method that has been in general use on living patients for some time.

ISAAC Gerber, M.D., Provideñee, R. I.

[A proof of the preceding was sent to Dr. Unger, who replies:]

To the Editor:-I wish to acknowledge with chagrin that Dr. Gerber is correct. My claim to originality was made in good faith since a roentgenologist with whom I discussed the method knew nothing of it and the literature consulted did not contain it. I missed the line in Knox's "Radiography" that mentions this method. May I congratulate Dr. Pfahler on devising such an excellent method.

Max Unger, M.D., New York.

\section{SPENCER'S CHLORAMINE PASTILLES}

To the Editor:-I notice on the market in local drug stores an article made by "John Wyeth \& Son, Sole Proprietors, Philadelphia," labeled "Spencer's Chloramine Pastilles" and recommended for "influenza" and other (similar) conditions. It is further stated that "as the name indicates," these pastilles are made up of ammonium chlorid and other substances (which are named), and contain opium.

In view of the fact that "chloramin" is the accepted name of p-toluene sulphochloramid, and that this substance has been recommended for use as a throat spray in connection with the present epidemic of influenza, it seems as though the "chloramine pastilles" were likely to deceive the public, and result in greater, rather than less danger to the people who do not know the nature of these substances, or their relative value.

Should not this be called to the attention of the medical profession, and if possible, of the general public?

S. C. Brooks, Boston.

[COMMENT.-The term "chloramin" is applied to a class of chemical compounds that contain group : $\mathrm{NCl}$. The chloramin derivative sodium paratoluenesulphochloramid has been called chloramin-T, the "chloramin" indicating the characteristic $\mathrm{NCl}$ group, and the " $\mathrm{T}$ " the derivation from toluene. Sodium parabenzenesulphochloramid has been called chloramin- $B$, the " $B$ " indicating its origin from benzene. Before chloramin-T and the related products came into use in medicine, John Wyeth and Brother had registered the term "chloramine" as a trademark for a pharmaceutical preparation which in no sense is a chloramin. This misuse of a chemical term is to be regretted and indicates the need for $\mathbf{a}$ revision of our trademark law which permitted the registration of this evidently misleading term.-ED.1

Native Customs and Cancer.-In parts of China where the head is shaved by public barbers, the razors used are often dull and full of nicks, and the irritation of this scraping often causes cancer. Chinese men suffer from cancer of the pharynx and esophagus due to their habit of eating very hot rice, which is thrown into the mouth forcibly with chop sticks. Chinese women eat after their lords and masters, when the rice is cold, and they never have this kind of cancer. In India much cancer is caused by the chewing of betel nut. In some parts of the country women do not chew the nut, and are free of cancer of the mouth. In Khurdistan, India, the natives wear baskets filled with hot coals across their abdomens to protect them from the cold, and more than 50 per cent. of all the cancer in that region forms in the abdomen and groin, while in other countries such cancers are very rare.-Major W. J. Mayo, War Department Lectures. 